\title{
Los trabajos de la memoria: la masacre de las bananeras y los sectores subalternos en Colombia, 1929-2008
}

Resumen: El artículo indaga de qué modo y bajo qué circunstancias fue evocada la masacre de las bananeras entre 1929 y 2008. El propósito es reflexionar sobre el papel de la memoria colectiva como articuladora de aspiraciones de justicia y de prácticas políticas en sectores subalternos de Colombia. Durante el período fue común la invocación del acontecimiento como una fecha infeliz a través de actos que estuvieron mediados por las circunstancias políticas del momento. Se concluye que la conmemoración de la masacre de las bananeras sirvió no solo para recordar, sino para forjar y fortalecer identidades políticas en sectores específicos de la población.

Palabras clave: masacre de las bananeras, memoria, sectores subalternos, identidades políticas.

\section{The works of memory: the masacre de las bananeras and the subaltern sectors in Colombia, 1929- 2008}

Abstract: The article examines how and under what circumstances the bananeras massacre was invoked between 1929 and 2008. The purpose is to study the role of collective memory as an articulator of justice aspirations and political practices in subaltern sectors of Colombia. During the period it was common to mention the event as an unhappy date, through acts that were mediated by the political circumstances of the time. The article concludes that the commemoration of the massacre de las bananerasserved not only to remember, but also to forge and strengthen political identities in specific sectors of the population.

Keywords: bananera massacre, memory, subaltern sectors, political identities.

\section{0 trabalho da memória: a masacre de las bananerase os setores subordinados na Colômbia, 1929- 2008}

Resumo: 0 artigo explora como e em que circunstâncias foram realizadas as derrubadas de plantações de banana entre 1929 e 2008. 0 objetivo é refletir sobre o papel da memória coletiva como um articulador das aspirações de justiça e práticas políticas em setores subordinados da Colômbia. Durante o período foi comum à invocação do acontecimento como uma data infeliz onde os atos foram mediados por circunstâncias políticas daquele momento. Conclui-se que a comemoração da masacre de las bananeras, serviu não só para lembrar, mas também, para forjar e fortalecer identidades políticas em setores específicos da população.

Palavras-chave: derrubada de bananeiras, memória, subordinados, identidades políticas.

Cómo citar este artículo: José Abelardo Díaz Jaramillo, "Los trabajos de la memoria: la masacre de las bananeras y los sectores subalternos en Colombia, 1929-2008”, Trashumante. Revista Americana de Historia Socia/13 [2019]: 30-54. DOI: 10.17533/udea.trahs.n13a02

Fecha de recepción: 12 de junio de 2017

Fecha de aprobación: 14 de mayo de 2018

José Abelardo Díaz Jaramillo: Doctor en Historia por la Universidad Nacional de Colombia. Profesor de la Corporación Universitaria del Meta.

Correo electrónico: jose.diaz@unimeta.edu.co 


\section{Los trabajos de la memoria: la masacre de las bananeras y los sectores subalternos en Colombia, 1929-2008}

José Abelardo Díaz Jaramillo

\section{Introducción}

E 6 de diciembre de 2008 personas procedentes de distintos lugares de Colombia

- y lugareños se reunieron en la plaza central de Ciénaga, municipio ubicado en el departamento de Magdalena, para recordar lo ocurrido el 6 diciembre de 1928, cuando un pelotón del ejército disparó contra una concentración de trabajadores que realizaban una huelga. El acto de 2008 estuvo precedido de una campaña que contempló múltiples actividades en distintas ciudades del país y que buscó poner de nuevo en el escenario público lo ocurrido ochenta años atrás. ¿Cómo explicar que numerosas personas dedicasen energías y recursos para recordar hechos que ocurrieron varias décadas atrás, y que ninguno vivió directamente? ¿Qué sentidos otorgaron a la fecha trágica? ¿Qué papel cumplieron los “actos de recordar" en quienes participaron en las conmemoraciones? Al recordar, ¿de qué modo lo hicieron? ¿Introdujeron nuevos elementos vivenciales provenientes de otras situaciones dramáticas? ¿Cambiaron los recuerdos del acontecimiento de una generación a otra? ¿Se conmemoró de una manera diferente a como se hizo en otras oportunidades?

Estas cuestiones serán abordadas en el artículo, para lo cual se tendrá como referente de caso lo que en Colombia se conoce como la masacre de las bananeras. La reflexión estará orientada desde dos perspectivas:

a. Una fecha dramática: la masacre de las bananeras como acontecimiento y el 6 de diciembre de 1928 como fecha simbólica han alimentado la memoria de los sectores subalternos del país. Que ello sea así lo demuestra la permanencia de su recuerdo. Se trata de una "fecha infeliz" que al ser evocada de manera reiterada ha dado origen a lo que Elizabeth Jelin denomina "conmemoraciones infelices".

1. Elizabeth Jelin, comp., Las conmemoraciones: Las disputas de las fechas "in-felices" (Madrid: Siglo XXI, 2002). 
b. La memoria como recurso político: el análisis de la conmemoración de la masacre de las bananeras permite constatar que diversos sectores sociales del país (denominados aquí sectores subalternos para referir a grupos de la población que por su condición social y económica ocupan una posición particular en la estructura de poder) han usado el recuerdo como un instrumento de confrontación con el poder hegemónico (que suele ser visto como heredero del que existía en 1928).

Como se observa, las dos perspectivas tienen en común la consideración de la memoria como un componente especial en el imaginario de los grupos sociales, un asunto que en tiempos recientes ha adquirido notable interés académico y político, a tal punto que puede hablarse de una "obsesión memorialista" en la sociedad contemporánea. ${ }^{2}$ Ese interés ha motivado el estudio de las conmemoraciones al considerar que en esos eventos surgen prácticas de memoria que suelen anidar conflictos que enfrentan diferentes interpretaciones del pasado. ${ }^{3}$

Al indagar la forma como los grupos sociales evocaron la masacre, se podrá evidenciar que tal acontecimiento operó como un referente simbólico promotor de prácticas sociales que se recrearon de distintas formas: ceremonias, mítines, peregrinaciones, etc. Por tal razón, la línea de interpretación del artículo establece que la memoria y, en particular, la conmemoración, estimulan formas de movilización política y promueven identidades colectivas que sirven para reforzar las representaciones que distintos sectores sociales tienen de sí y de los otros (Estado, élites, fuerzas armadas, etc.). Como sostiene Stéphane Michonneau, la memoria no solo es discurso sobre el pasado, sino que también está relacionada con la formación de identidades colectivas. ${ }^{4}$

Siguiendo a Elizabeth Jelin, se argumentará que la fecha de la masacre sirvió para activar la memoria colectiva al constituirse en un espacio abierto donde grupos sociales otorgaron sentidos diversos a lo ocurrido en diciembre de $1928 .{ }^{5}$ En la misma dirección se mostrará que los actos de recordar se dieron en contextos de tensión política que incidieron notablemente en la forma como se representó lo ocurrido en 1928. Por último, se demostrará que en torno a la evocación de la masacre de las bananeras los grupos sociales promovieron referentes identitarios que reforzaron sus representaciones acerca de la vida pública.

De tal modo, se analizarán las evocaciones en tres momentos diferentes a partir de la evidencia de que en ellos se otorgó una especial importancia al ejercicio de recordar la masacre: 1929, 1978 y 2008. Como se verá, en cada momento se registraron situaciones particulares que incorporaron al discurso evocador de la masacre nuevos ingredientes interpretativos, con lo cual se demostrará que la memoria suele estar marcada por situaciones del presente. De hecho, siguiendo a Maurice

2. Enzo Traverso, El pasado, instrucciones de uso. Historia, memoria, política (Barcelona: Marcial Pons, 2007) 16.

3. Jelin 2 .

4. Stéphane Michonneau, "La memoria, ¿objeto de historia?", Identidades y memoria imaginada, eds. Justo Beramendi y María Jesús Baz (Valencia: Universitat de Valencia, 2008) 48 y 50.

5. Jelin 245 . 
Halbwachs, se concluirá que el pasado no se conserva, sino que se reconstruye a partir del presente: el pasado sirve para justificar las representaciones del presente. ${ }^{6}$

\section{1929: la proximidad del suceso}

1929 fue decisivo para Colombia por varias razones: fue el año en que estalló la crisis económica internacional, la cual originó hondas calamidades internas que se expresaron en movilizaciones sociales en campos y ciudades; también fue el año en que se agudizó la crisis política que selló el destino de la Hegemonía Conservadora y allanó el camino para que el liberalismo arribara al poder. Esa crisis se alimentó de acontecimientos como la masacre de las bananeras, que con relativa fuerza comenzó a gravitar de nuevo entre los colombianos a raíz de las jornadas de protesta que estallaron en Bogotá en junio de 1929 y del fogoso debate que adelantó el representante liberal Jorge Eliécer Gaitán en el Congreso de la República en septiembre de 1929. Los dos acontecimientos otorgaron a los hechos de diciembre de 1928 una notoria visibilidad, además, unidos al impacto de las caricaturas mordaces que sobre el asunto publicó Ricardo Rendón en El Tiempo, impidieron que la administración conservadora lograra pasar definitivamente la página de aquel luctuoso hecho. Como ha sido resaltado en investigaciones sobre el período, fue enorme el peso político que debió pagar la presidencia de Miguel Abadía Méndez por los sucesos de 1928 en Magdalena.

Vistos en conjunto, los hechos mencionados demuestran que tiempo después de ocurrida la masacre esta continuaba circulando en la sociedad colombiana, invocada generalmente en clave de deseo de justicia. ${ }^{7}$ Para ilustrar esa tesis, a continuación se abordarán tres coyunturas que estuvieron relacionadas con la evocación de la masacre de las bananeras en 1929.

\subsection{Las protestas de junio de 1929}

En los primeros días de junio de 1929 se desataron en Bogotá protestas, motivadas por la inconformidad que suscitó la presencia de un grupo de funcionarios municipales ligados a prácticas corruptas. Estos hechos, que se conocieron posteriormente como las "jornadas contra la rosca", contribuyeron al deterioro del régimen conservador, algo que se venía acentuando desde hacía algún tiempo. En el debilitamiento del régimen desempeñó un papel especial la masacre de las bananeras, ocurrida siete meses atrás, y cuyo recuerdo permanecía aún fresco, pese a que desde el Estado se intentó promover el olvido del acontecimiento.

Las protestas en junio de 1929 adquirieron grandes proporciones, lo cual se explica, en parte, porque tanto el presidente Miguel Abadía Méndez como el

6. Maurice Halbwachs, Los marcos sociales de la memoria (Barcelona: Anthropos, 2004).

7. Medófilo Medina, Historia del Partido Comunista de Colombia (Bogotá: Centro de Estudios e Investigaciones Sociales, 1980) 150. 
comandante de policía Carlos Cortés Vargas, implicados en los hechos de 1928, aparecían ahora como responsables de la represión que se empleaba para contener a los manifestantes en las calles de Bogotá. La presencia de estas dos figuras alimentó la indignación social que se fortaleció luego del asesinato del estudiante Gonzalo Bravo Pérez la noche del 7 de junio. ${ }^{8}$

Un aspecto visible en las movilizaciones callejeras de junio de 1929 fue la representación de un sentimiento de justicia por lo ocurrido en diciembre de 1928. En efecto, la inconformidad ciudadana por la impunidad que había reinado por la masacre se vio recreada en las calles cuando los manifestantes evocaron lo sucedido en Ciénaga, empleando carteles que contenían símbolos alusivos a la muerte de los trabajadores y frases como "Venimos del Magdalena", "Venimos de las Bananeras", "Abajo Cortés Vargas" (Figura 1). Se transmitía así al gobierno conservador el mensaje de que quienes estaban insubordinados en las calles de Bogotá eran los mismos que meses atrás habían participado en la huelga bananera. Evidentemente, también se quería transmitir el mensaje de que, pese al tiempo transcurrido, los responsables intelectuales y materiales de la masacre, que eran los mismos que estaban vinculados, como así se veía, a los sucesos de junio de 1929 en Bogotá, debían ser juzgados. Precisamente, uno de los protagonistas de las protestas de junio, el joven Jorge Eliécer Gaitán, pudo advertir en las calles de la ciudad la presencia de una memoria activa sobre la masacre de las bananeras, lo que debió motivarlo para concebir la idea de promover un debate en el Congreso sobre ese acontecimiento algunas semanas después.

Figura 1. Manifestantes en Bogotá en junio de 1929 portando carteles que aluden a la masacre de las bananeras

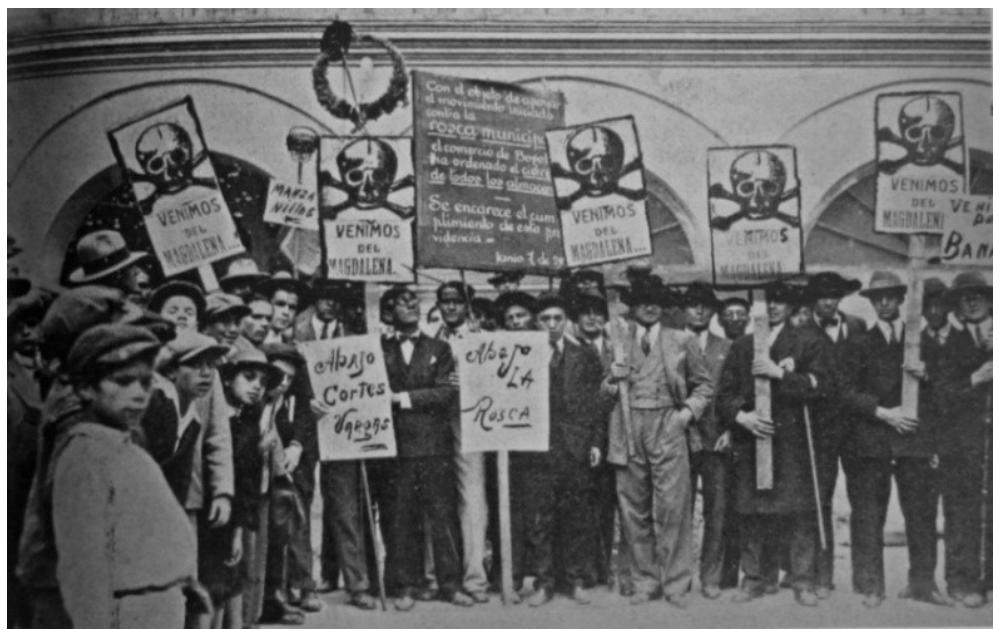

Fuente: Renán Vega, Gente muy rebelde, t. 3 (Bogotá: Pensamiento Crítico, 2002) 189.

8. El suceso ha sido estudiado, entre otros, por Medófilo Medina, La protesta urbana en Colombia en el siglo XX (Bogotá: Ediciones Aurora, 1984); Renán Vega Cantor, Gente muy rebelde, t. 3 (Bogotá: Pensamiento Crítico, 2002). 


\subsection{El debate sobre las bananeras}

Fueron célebres las intervenciones del parlamentario Jorge Eliécer Gaitán en la Cámara de Representantes en septiembre de 1929, las cuales buscaban, según manifestó el dirigente liberal, establecer la responsabilidad del Estado en la muerte de los trabajadores bananeros. ${ }^{9}$ Junto a las protestas ocurridas tres meses atrás, y a las caricaturas mordaces de Ricardo Rendón, ${ }^{10}$ las intervenciones de Gaitán en el parlamento sirvieron no solo para mantener vigente en la memoria ciudadana los hechos de 1928, sino, y es algo de sumo valor, para generar un ambiente favorable para reivindicar la aplicación de justicia a los responsables de la tragedia.

Antes de que estallara la huelga bananera en noviembre de 1928, Jorge Eliécer Gaitán ya descollaba como una emergente figura juvenil del liberalismo. En 1924 había sido elegido diputado a la Asamblea Departamental de Cundinamarca, y para 1929 era conocido como un "bolchevique radical" por la invocación que hacía de las masas y de la cuestión social. ${ }^{11}$ El interés de Gaitán por los sucesos de las bananeras, de los cuales se enteró mientras estaba en París, le sirvió para ganar audiencia a nivel nacional. En su condición de representante electo, y semanas antes de posesionarse, Gaitán anunció su pretensión de realizar un debate en la Cámara para establecer cuál había sido la responsabilidad del gobierno de Miguel Abadía Méndez en los sucesos de la zona bananera el año anterior. De igual modo, expresó que visitaría la región con el propósito de obtener información sobre lo ocurrido allí.

Consecuente con su anuncio, el 13 de julio Gaitán arribó a Barranquilla y pronto se dirigió a Ciénaga y a otras poblaciones vecinas que habían sentido los efectos de la huelga de los trabajadores de 1928. Según cuenta un biógrafo del líder, el interés del político por ir a esos lugares era "hablar con las viudas, con los huérfanos, con los sobrevivientes de los hogares humildes, condenados al agobiador trabajo infecundo", ${ }^{12}$ comportamiento que despertó una impresión especial

9. Las intervenciones de Jorge Eliécer Gaitán fueron editadas en diversas oportunidades. La primera edición data de 1929, titulado Lágrimas y sangre, o, las matanzas en las bananeras: compilación de los debates en el congreso alrededor de los procesos militares (Cali: Ediciones de la Tipografia Gutenberg, 1929). En 1972, dos editoriales dedicadas a promover textos de izquierda (Ediciones Libres y Ediciones Los Comuneros), nuevamente publicaron los debates de Gaitán. Apartes de la intervención de Jorge Eliécer Gaitán fueron compilados por Santiago Perry, comp., Escritos políticos (Bogotá: El Áncora Editores, 1985). La versión más completa en El debate sobre las bananeras. Cuatro días de verdad contra 40 años de silencio (Bogotá: Centro Cultural Jorge Eliécer Gaitán, 1988).

10. Las caricaturas de Ricardo Rendón fueron fundamentales para crear un marco de opinión que presionó la caída del régimen conservador.Véase German Colmenares, Ricardo Rendón: una fuente para la historia de la opinión pública (Bogotá:Tercer Mundo / Universidad del Valle / Banco de la República, 1998).

11. Joy Cordell Robinson, El movimiento gaitanista en Colombia (1930-1948) (Bogotá:Tercer Mundo, 1976) 55.

12. José Antonio Osorio Lizarazo, Gaitán: vida, muerte y permanente presencia (Bogotá: Carlos Valencia Editores, 1979) 115. La indagación que Jorge Eliécer Gaitán realizó en la costa norte del país, 
en los pobladores tal y como lo registró la prensa. ${ }^{13}$ Una nueva visita de Gaitán a la zona, pocos días después, fue comentada en los siguientes términos por un corresponsal de la prensa barranquillera:

Acaba de regresar a esta ciudad el doctor Jorge Eliécer Gaitán, de su segundo viaje a la zona bananera. Los descubrimientos que ha hecho son verdaderamente macabros y terribles. Cuando el país conozca la formidable documentación levantada por el doctor Gaitán, sentirá angustia, desconcierto y dolor por el patriotismo ultrajado, lo mismo que todos aquí sienten ante el mismo conocimiento de hechos que permanecían ocultos, antes de la llegada del doctor Gaitán. ${ }^{14}$

Durante el tiempo que permaneció en la zona bananera, Gaitán recogió información sobre los sucesos ocurridos, que incluía declaraciones de personas que manifestaron haber sido agredidas o que presenciaron las ofensas y arbitrariedades del ejército. ${ }^{15}$ En ese material probatorio se apoyó el dirigente liberal para expresar a un diario, con un evidente interés efectista que daba luces del calibre de las tesis que esgrimiría en el Congreso: "Si sigo aquí, iré derecho al manicomio ante tantos horrores". ${ }^{16}$

El 20 de julio de 1929 Gaitán se posesionó como representante a la Cámara. Ese día, en la instalación de las sesiones del nuevo Congreso, el presidente Miguel Abadía Méndez presentó un informe sobre lo ocurrido el año anterior en Cienaga. ${ }^{17}$ Sin embargo, la lectura que presentó el primer mandatario de los hechos fue duramente desvirtuada semanas más tarde por Gaitán, cuando este dio inicio al que sería considerado como uno de los más famosos debates en la historia parlamentaria de Colombia. ${ }^{18}$ El historiador Joy Cordell Robinson describió el sonado debate en los siguientes términos:

Durante los quince días siguientes, Gaitán retuvo continuamente la atención del Congreso describiendo en detalle la arbitrariedad de la concesión de tierras a la Compañía y el casi ilimitado poder que ella había adquirido allí [...] En el curso del debate, Gaitán demolió los intentos de los voceros gubernamentales de impugnar sus aseveraciones [...] La acción de Gaitán en la Cámara de Representantes atrajo a estudiantes, diplomáticos y altos empleados oficiales, quienes nutrieron las galerías de ese recinto para oír su apasionada oratoria y observar sus actuaciones teatrales [...] Al final de cada sesión, centenares de admiradores se reunían a las puertas del Capitolio

previa al debate en el parlamento, fue interpretada por un estudioso de su proyecto político como una "investigación algo teatral". William John Green, Gaitanismo, liberalismo de izquierda y movilización popular (Medellín: Fondo Editorial Universidad EAFIT / Banco de la República, 2013) 113.

13. La Prensa (Barranquilla) 15 de julio de 1929: 5.

14. El Tiempo (Bogotá) 17 de julio de 1929: 1.

15. Judith White, Historia de una ignominia: la United Fruit Co. en Colombia (Bogotá: Editorial Presencia, 1978) 107.

16. Citado en Urrutia 130.

17. La Prensa (Barranquilla) 24 de julio de 1929: 2.

18. Urrutia 130. 
para llevarlo en hombros, entre 'vivas', a través de las calles de Bogotá, hasta su residencia situada a pocas cuadras. ${ }^{19}$

Sin duda el debate fue concebido como un recurso para acusar al gobierno conservador. De ahí que Gaitán sacara provecho de su formación como penalista para apelar a situaciones en las que puso a circular términos como "gran tragedia" o "cruel tragedia" y, de esta manera, referirse a los sucesos de las bananeras a los que catalogó como "delitos de lesa patria", cometidos por "hombres despiadados e inmisericordes". Gaitán logró, de ese modo, posicionar una representación trágica de lo ocurrido en la zona bananera, que al ser recreada por la prensa liberal que cubría las sesiones en el parlamento despertó en poco tiempo un sentimiento de indignación en la ciudadanía. Al cuestionar con dureza la forma como el Estado y el ejército actuaron en el conflicto laboral, Gaitán consiguió, además, la aprobación de una ley que disponía la revisión de las sentencias proferidas a las personas acusadas de participar en la huelga bananera, y establecía compensaciones económicas a las viudas y los hijos de trabajadores que fueron víctimas de la acción de los militares. La revisión de las sentencias y el resarcimiento económico a las víctimas fueron catalogadas como un triunfo del joven parlamentario, al lograr que el debate promovido por él fuese considerado como "la primera defensa del pueblo colombiano desde el recinto del congreso de que tuvieron memoria los bogotanos". ${ }^{20}$

\subsection{La candidatura presidencial de Alberto Castrillón}

Además de contender el liberal Enrique Olaya Herrera y el conservador Guillermo Valencia, en las elecciones presidenciales de 1930 participó como candidato Alberto Castrillón a nombre del Partido Socialista Revolucionario (PSR). El hecho era significativo, ya que por primera vez el socialismo colombiano se aprestó a participar en una elección presidencial con un candidato salido de sus entrañas.

La escogencia de Alberto Castrillón - decisión tomada por el comité central del PSR - respondía al interés de la dirigencia revolucionaria por establecer una conexión entre la aspiración política del PSR y la masacre de las bananeras, ya que Castrillón había participado en la huelga bananera de 1928 como asesor de los trabajadores. Por ese hecho, precisamente, Castrillón fue detenido y sometido por las autoridades militares a un consejo de guerra que lo condenó a pagar una pena de varios años de cárcel. No obstante, quedó libre en noviembre de 1929 al ser cobijado por una ley que ordenó revisar los procesos condenatorios, como resultado del debate que realizó Jorge Eliécer Gaitán en el parlamento. ${ }^{21}$

19. Cordell 56.

20. Herbert Braun, Mataron a Gaitán.Vida pública y violencia urbana en Colombia (Bogotá: Universidad Nacional de Colombia, 1987) 41-42. Pocos meses más tarde el Congreso aprobó una amnistía para 300 trabajadores que habían sido sentenciados a penas de entre 10 y 20 años.

21. En prisión Alberto Castrillón escribió un texto en el que relata su participación en la huelga y lo ocurrido después de la masacre.Véase Alberto Castrillón, 120 días bajo el terror militar o la huelga de 
Sin duda las posibilidades de triunfo de Castrillón en la contienda presidencial eran mínimas. Sus copartidarios así lo entendían y no se prestaban a engaños. ${ }^{22}$ En verdad, para la militancia socialista la importancia de participar en las elecciones de 1930 debía buscarse en un escenario distinto: el simbólico. Ignacio Torres Giraldo, sin vacilar, lo reconoció al revisar el comportamiento de la dirigencia revolucionaria en aquel año:

¿Era acertada la elección de Castrillón para candidato? Sin lugar a duda. Castrillón, no había sido un aguerrido dirigente de masas ni lo fue después. Pero había sido uno de las víctimas del terror militar en la Zona Bananera y simbolizaba la gran masa de trabajadores que se había enfrentado al pulpo yanqui United Fruit y sus lacayos nacionales. ${ }^{23}$

La confesión de Torres Giraldo ayuda además a entender por qué la fecha escogida para lanzar la campaña socialista fue el 6 de diciembre de 1929: ese día se cumplía el primer aniversario de lo ocurrido en Ciénaga un año atrás. ${ }^{24}$ El comité central del PSR así lo dispuso, como se lee en una comunicación que circuló internamente:"Proclamación oficial deberá hacerse en todo el país el 6 de diciembre próximo, primer aniversario masacre Zona Bananera. Procedan organizar comités pro-campaña electoral candidato del proletariado obrero y campesino". ${ }^{25}$ Rafael Baquero, entonces miembro de la dirección socialista, recuerda el acto de lanzamiento de la campaña de Castrillón en Bogotá así:

Fue un acto sumamente interesante y lo recuerdo muy bien por varios motivos [...] El Teatro Municipal, donde se hizo el acto, estaba completamente lleno a las cinco de la tarde que era la

las bananeras (Bogotá: Revista Universidad, 1929). Para divisar las primeras reacciones que suscitó el libro de Castrillón, tal vez el primer escrito que menciona la masacre de las bananeras, vale la pena recrear el comentario que desde las páginas de la revista Universidad se hizo del autor del libro: "Alberto Castrillón, en un pequeño libro sereno, ponderado y sencillo, en donde se habla de la patria con el mismo ardor romántico que han condenado los apóstoles de las extremas izquierdas, se presenta ante el tribunal de la opinión pública como un hombre juicioso y sensato que contrasta rudamente con el general Cortés Vargas”. Universidad (Bogotá) 27 de julio de 1929.

22. A las pocas semanas de ser lanzada la candidatura de Castillón, esta fue cuestionada porVictorio Codovilla, jefe de la Internacional Comunista, organismo al que había adherido el PSR, al aducir que Castrillón tuvo un comportamiento antirrevolucionario al acudir a instancias jurídicas para solicitar su liberación cuando estuvo preso por los hechos de diciembre de 1928. Si bien la candidatura siguió su curso, esta se vio afectada por el reclamo de Codovilla. Klaus Meschkat y José María Rojas, comps., Liquidando el pasado. La izquierda colombiana en los archivos de la Unión Soviética (Bogotá:Taurus / Fescol, 2009).

23. Ignacio Torres Giraldo, Los inconformes. Historia de la rebeldía de masas en Colombia, t. 4 (Bogotá: Editorial Latina, 1978) 1006.

24. Los hechos de Ciénaga también motivaron la acción de otros sectores políticos, como ocurrió en la campaña del candidato liberal Enrique Olaya Herrera, que incluyó en la gira por la costa Atlántica una rápida visita a la zona bananera. White 109.

25. Meschkat y Rojas, 305. 
proclamación y quedó mucha gente por fuera [...] Este acto tuvo lugar el 6 de diciembre de 1929 , con motivo del primer aniversario de la matanza de las bananeras. ${ }^{26}$

Posterior al acto del Teatro Municipal, los militantes recorrieron algunas calles portando carteles con mensajes alusivos al aniversario de la masacre de las bananeras. Luego se concentraron en las puertas del Cementerio Central, lugar en donde homenajearon a los trabajadores muertos en $1928 .{ }^{27}$ Tanto la movilización por las calles como la concentración en el cementerio tenían un significado especial al tratarse de la primera — y de hecho, única manifestación pública— realizada en la capital de la república durante un largo período con ocasión de la trágica fecha.

¿Qué se puede identificar en este primer momento? Evidentemente, hay una fuerte presencia del recuerdo del acontecimiento, hecho que estaría atado a la inmediatez del mismo. Que no hubiese transcurrido mucho tiempo - apenas unos meses - incidió para que el recuerdo de la masacre de las bananeras permaneciera activo en el escenario público y para que de él hicieran uso distintos sectores políticos. Sin embargo, era necesario crear condiciones para que el recuerdo pudiese aflorar en los espacios públicos, sorteando los obstáculos que trataban de impedirlo. Es acá donde adquirieron protagonismo las estrategias que se emplearon para ese propósito: manifestaciones callejeras, debates en el parlamento y lanzamiento de una candidatura presidencial el 6 de diciembre de 1929, entre otras.

Los actos de recordar aquel momento fueron promovidos por dos fuerzas políticas que estuvieron interesadas en mantener vigente el recuerdo de lo ocurrido en 1928: el liberalismo (que aspiraba a convertirse en fuerza gobernante) y el socialismo revolucionario (que había sido duramente golpeado por la acción del Estado antes y después de la huelga bananera). Sin embargo, las razones eran distintas para cada una de las fuerzas políticas mencionadas. Para el liberalismo, por ejemplo, recordar la masacre y asociarla al régimen conservador era indispensable para minar las bases sobre las que se erigía este último y, de esta manera, fortalecer su aspiración de acceder al gobierno en 1930.

¿Qué pasó con el recuerdo de la masacre de las bananeras después de 1929? Aquí el hecho que más llama la atención es constatar que luego de 1930 el liberalismo continuó evocando la masacre, aunque tímidamente, para luego con el paso de los años dejar a un lado su evocación como acontecimiento trágico. Para mostrar que operó en el liberalismo un proceso de selección de lo que debía ser recordado, puede hacerse mención a la fecha del 8 de junio (que hacía referencia a las jornadas contra la rosca en 1929), la cual sí fue evocada por el liberalismo de forma reiterada a tal punto que fue convertida en una efeméride clásica que se articuló al activismo político de ese partido durante las décadas siguientes. La suerte de la masacre de las bananeras, en cambio, fue diferente al ser objeto de interés, en

26. Carlos Arango Z., Forjadores de la revolución colombiana (Bogotá: Editorial Colombia Nueva, 1983) 201-202.

27. Para una descripción más detallada del acto conmemorativo realizado en Bogotá ese 6 de diciembre de 1929, véase Meschkat y Rojas 311. 
particular, por las fuerzas de izquierda: concretamente del Partido Comunista (PC), que surgió como reemplazó del PSR.

\section{1978: los cincuenta años de la masacre de las bananeras}

Con el paso de los años, la presencia de la masacre de las bananeras como acontecimiento infeliz pareció diluirse. Después de 1929 casi que desapareció del debate político, y apenas si fue evocada por los reducidos sectores políticos de izquierda, lo cual acontecía cada vez que se aproximaba la fecha del 6 de diciembre. Como ya se anotó, las razones que explicarían ese hecho, que contrasta con lo ocurrido al final de 1929, tendrían que ver, de un lado, con que para el liberalismo - fuerza política en el poder- el acontecimiento ya no tenía la misma carga simbólica que tuvo en el último año de la Hegemonía Conservadora. Además, porque la izquierda, único sector interesado - por sus vínculos con el sindicalismo y los trabajadores - en sostener el recuerdo de la masacre, carecía del capital político necesario para poder hacerlo con más intensidad.

En los años sesentas, sin embargo, el asunto comenzó a cambiar. En 1967 Gabriel García Márquez publicó Cien años de soledad, novela en la que la masacre de las bananeras es convertida en un episodio central en la historia de Macondo, ligada a los efectos negativos de la United Fruit Company (UFCO) en la región bananera. En Cien años de soledad la euforia por la llegada de la empresa se transformó con el paso del tiempo en una tragedia que tuvo su máxima expresión con la masacre, un hecho sangriento que marcó la vida de los pobladores, quienes, además, fueron contagiados de la "peste del olvido": un dispositivo político que, en clave de la narrativa de García Márquez, se impuso para borrar lo ocurrido. ${ }^{28}$

La referencia a la masacre de las bananeras en Cien años de soledad tuvo efectos notables. Entre los más destacados sobresale el de haber conseguido que el hecho trágico trascendiera las fronteras nacionales y que varias generaciones de colombianos nacidos en fecha posterior a 1928 conocieran por primera vez, desde la ficción literaria, un suceso que antes ignoraban. ${ }^{29}$ Parecía que el recuerdo de la masacre de las bananeras, para emplear una figura literaria de la novela, volvía a tener una posibilidad sobre la tierra. Lo singular del suceso es que su presencia estaba mediada por la lectura y no por rituales políticos, algo que, por cierto, se había ensayado anteriormente en otras publicaciones literarias, aunque sin el mismo impacto que

28. Gabriel García Márquez, Cien años de soledad (Bogotá: Editorial Sudamericana, 1967). La interpretación de la masacre de las bananeras en la novela tuvo efectos en la representación del acontecimiento Por ejemplo, sobre el número de muertos — en boca de José Arcadio Segundo, el único sobreviviente de la masacre—, García Márquez puso una cifra superior a los tres mil trabajadores asesinados, lo cual sirvió para instaurar en la memoria la idea de la magnitud de lo ocurrido.

29. La dimensión continental de la novela se recrea en las múltiples ediciones que debieron hacerse luego de que la primera, publicada en Buenos Aires en 1967, se hubiese agotado rápidamente; y el merecimiento del Premio Rómulo Gallegos que obtuvo García Márquez ese mismo año. Álvaro Tirado Mejía, Los años sesenta. Una revolución en la cultura (Bogotá: Debate, 2014) 115. 
alcanzó la obra del escritor de Aracataca. ${ }^{30}$ Los lectores de la novela de García Márquez eran habitantes de ciudad, ligados a las clases medias — profesionales, estudiantes universitarios-, lo que garantizó un nuevo público que tuvo acceso - por primera vez en sus vidas - al acontecimiento.

Si bien desde la literatura se recuperó el acontecimiento infeliz, la política continuó siendo el escenario natural para evocarlo. En 1968, a cuarenta años de ocurrido el suceso, los comunistas nuevamente acudieron al recuerdo de la masacre. Al hacerlo retomaron la idea de la "peste del olvido" de la que habló García Márquez para indicar que, pese a la pretensión de "los verdugos, los abogados del monopolio yanqui y sus testaferros" de que el "pueblo colombiano" olvidara "semejante crimen", existía una voluntad de no pasar la página. No era difícil advertir en ese razonamiento una articulación entre el "deber de memoria" y el "deber de justicia", ${ }^{31}$ que fortalecía precisamente el ejercicio de recordar. Al referirse a la masacre de las bananeras indicaban los comunistas:

El pueblo colombiano, con la clase obrera a la cabeza, no olvida el crimen perpetrado hace cuarenta años en la zona bananera del Magdalena. Y espera la hora de llamar a cuentas a los mismos que, ayer como hoy, siembran la muerte, la violencia y el terror en los campos y en las concentraciones urbanas. ${ }^{32}$

Como se puede apreciar, aquí el acto de recordar estaba o pretendía ser conectado con las circunstancias del presente (1968). El acto de justicia invocado debía servir para sanar las heridas de 1928, pero también las que se habían abierto desde ese momento (“ayer como hoy”). Veamos cómo se argumenta esa postura, cuarenta años después, mediante la identificación de nuevos ropajes y modalidades:

De estos cuarenta años transcurridos, los últimos veinte años han sido de estado de sitio, bajo el cual los obreros han tenido que sepultar a sus compañeros asesinados por las armas oficiales, como en Santa Bárbara en 1963, bajo el gobierno de coalición oligárquica, mientras que vastas zonas campesinas han estado más de una vez enfrentadas a la 'política de sangre y fuego' de los tiranos de turno [...] Los altos mandos militares, al igual que en 1928, administran su arbitraria 'justicia' mediante escandalosos 'consejos verbales de guerra' o aplicando la 'ley de fuga', cuando no organizando bandas de pistoleros para asesinar cobardemente a los opositores de la oligarquía y el imperialismo yanqui. ${ }^{33}$

30. Nicolás Pernett, "La masacre de las bananeras en la literatura colombiana", Bananeras. Huelga y masacre. 80 años, eds. Mauricio Archila Neira y Leidy Torres Cendales (Bogotá: Universidad Nacional de Colombia, 2009) 193-227.

31. Paul Ricoeur, La memoria, la historia, el olvido (Buenos Aires: Fondo de Cultura Económica, 2008).

32. "En el 40 aniversario de la matanza de las bananeras", Voz Proletaria (Bogotá) 5 de diciembre de 1968.

33. "En el 40 aniversario". No se tiene registro de actividades públicas de organizaciones políticas y sociales ese año. 
La lectura elaborada por los comunistas en 1968 sobre la masacre de las bananeras constata la presencia de lugares comunes que serán retomados en otras oportunidades por distintas organizaciones, como se demostrará enseguida.

\subsection{La izquierda y los cincuenta años de la masacre de las bananeras}

En 1978 distintos sectores de izquierda y el Consejo Nacional Sindical, que reunía a las cuatro centrales de trabajadores, desplegaron esfuerzos para organizar la conmemoración de los cincuenta años de la masacre de las bananeras, con lo que dieron origen a un acontecimiento único en la historia de su evocación..$^{34}$ En efecto, los movimientos de izquierda (comunistas, maoístas, troskistas) impulsaron múltiples actividades en torno a la conmemoración, algunas coordinadas conjuntamente y otras de forma independiente, lo que hizo posible una coyuntura sumamente rica en actos políticos de memoria. Como no había ocurrido nunca en años anteriores, la conmemoración de 1978 se nutrió de dinámicas como la erección de monumentos, concentraciones públicas, conciertos musicales, montaje de obras de teatro y publicaciones.

¿Qué factores hicieron posible que en 1978 el acto de recordación de la masacre de las bananeras tuviera esa magnitud? Una razón radica en la transformación que había operado en el campo de la izquierda colombiana, constituida en ese momento por un conjunto variado de fuerzas (partidos, movimientos, organizaciones guerrilleras), algo muy distinto a lo que había ocurrido en décadas pasadas. Estas fuerzas políticas que contaban con formas de comunicación (prensa, revistas) y redes (particularmente en el ámbito cultural y académico) tenían, a su vez, aceptación en sectores urbanos, particularmente ligados al contexto intelectual y universitario, además del obrero. Por tal motivo, puede establecerse que la representación de la masacre de las bananeras, hasta ese momento siempre reducida al ámbito del sindicalismo, para 1978 parecía haberse extendido a otros sectores sociales por medio de diferentes formatos como la novela, el teatro, la investigación histórica y la prensa política.

No obstante reconocer que era heterogénea la izquierda de ese momento, existía una narrativa común sobre los hechos de Ciénaga en la cual se concebía la masacre de los trabajadores bananeros como el "bautismo de sangre" de la clase obrera en Colombia. ${ }^{35}$ Además, la conmemoración de los cincuenta años de la masacre fue concebida como una oportunidad para ir más allá del acto de recordar el acontecimiento trágico. También permitía que cada fuerza política puliera su interpretación de la política nacional, fortaleciera los niveles de compromiso de su militancia y ampliara el radio de acción o influencia política.

34. Valga anotar que el ejercicio de rememorar la masacre ha sido casi que exclusivo de sectores (partidos, movimientos, expresiones) ubicados en el campo de la izquierda política de Colombia, con alguna presencia de corrientes del liberalismo popular.

35. Una narrativa que debió beber de la interpretación de Torres Giraldo consignada en Los inconformes y de los debates de Jorge Eliécer Gaitán, reunidos y publicados en varias ediciones como se anotó en la nota 9. 
Para el Movimiento Obrero Independiente y Revolucionario (MOIR), el Partido Socialista de los Trabajadores (PST) y el PC —al igual que para otras organizaciones de izquierda - la historia nacional era un referente de inagotables lecciones que los sectores populares debían conocer en aras de afrontar con mejores herramientas las luchas del presente. Lo anterior explica, por ejemplo, las ingentes energías que el MOIR desplegó para que los actos conmemorativos de la masacre tuvieran un impacto significativo en la sociedad colombiana. ${ }^{36}$ Desde Tribuna Roja, su órgano de prensa, esa organización informó sobre los eventos que se realizarían en Ciénaga en diciembre de ese año y publicó notas de carácter histórico en las que reseñaba la presencia de la UFCO en la costa Atlántica, el sometimiento de los trabajadores a las condiciones de la empresa sin que estos recibieran la protección del Estado colombiano, así como el origen de la huelga y el trato que a esta le dio Carlos Cortés Vargas.

El PST también otorgó a los actos conmemorativos de 1978 un valor especial. A través de su órgano periodístico, El Socialista, resaltó la importancia de recordar a los trabajadores bananeros sus "primeros actos de insubordinación contra los patronos y el capital". ${ }^{37}$ Los editores de la revista Alternativa — ampliamente leída en el país en aquel momento - también se sumaron a los actos de conmemoración de la masacre, dedicando la célebre sección "La historia prohibida" a la reconstrucción del contexto histórico de la huelga de los trabajadores bananeros y los sucesos del 6 de diciembre de $1928 .{ }^{38}$

Entre las formas de recordar la masacre de las bananeras que se desplegaron en 1978 sobresalió el teatro, una actividad promovida desde la década anterior por grupos de artistas que hacían parte — en unos casos de manera directa- de las distintas fuerzas de izquierda. ${ }^{39}$ Para el quincuagésimo aniversario, se presentaron las obras "Huelga de las Bananeras”, de Jaime Díaz, y "El Sol Subterráneo”, de Jairo Aníbal Niño, elaboradas en años anteriores, pero que fueron de nuevo montadas en distintos escenarios del país. Esto en un marco social y político en el que, como reseñó El Socialista, se programaron jornadas de teatro "para obreros y explotados" en ciudades como Cartagena, Barranquilla, Santa Marta y Ciénaga para conmemorar "el 50 aniversario de la masacre de las Bananeras".40

36. Una referencia a los preparativos y sentidos otorgados por los militantes del MOIR a la conmemoración de la masacre bananera en 1978 se encuentra en la novela de Juan Diego Mejía, Soñamos que vendrían por el mar (Bogotá: Alfaguara, 2016). Lo narrado por Mejía coincide con lo expresado en documentos y testimonios de militantes de ese movimiento.

37. El Socialista (Bogotá) 31 de octubre de 1978: 5.

38. Carlos Alfonso Low Padilla, autor de las notas publicadas en Alternativa, había escrito años atrás una tesis sobre los conflictos laborales en la zona bananera. Carlos Alfonso Low Padilla, "Conflictos agrarios en la zona bananera: 1910-1947” (Tesis de grado en Sociología, Universidad Nacional de Colombia, 1972).

39. Mayra Natalia Parra Salazar, ${ }_{j}$ A teatro camaradas! Dramaturgia militante y politica de masas en Colombia (1965-1975) (Medellín: Fondo Editorial FCSH, 2015).

40. El Socialista (Bogotá) 31 de octubre de 1978: 5. 
Figura 2. Actos en Ciénaga. Al fondo, el monumento Prometeo de la Libertad

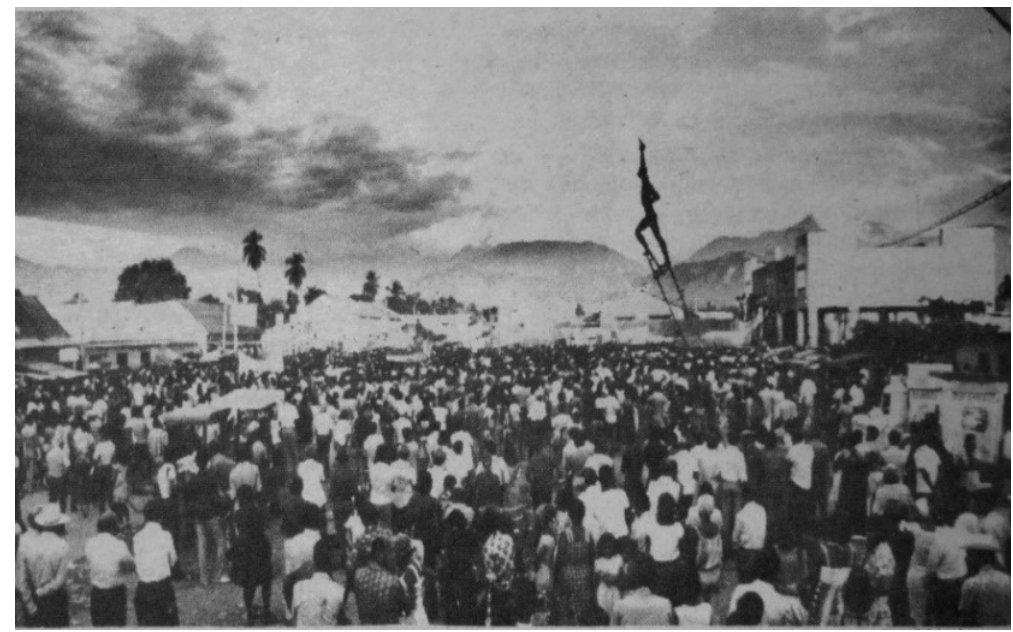

Fuente: Tribuna Roja (Bogotá) febrero-marzo de 1979: 17.

Otro mecanismo empleado en 1978 para evocar la masacre de las bananeras fue el levantamiento de un monumento alusivo a los trabajadores asesinados, el cual continúa en pie en Ciénaga. ${ }^{41}$ El monumento elaborado por el maestro Rodrigo Arenas Betancourt, denominado Prometeo de la Libertad, se convirtió en objeto de discusión. ${ }^{42}$ Finalmente, otro recurso que estuvo presente en los actos conmemorativos de 1978 fue la concentración pública. Al respecto, en distintas capitales del

41. La idea de erigir un monumento alusivo a la masacre de las bananeras no era nueva. En 1939, la Federación de Trabajadores del Magdalena solicitó al Concejo de Santa Marta permiso para levantar un "monumento a los mártires de la huelga bananera". Paralelamente, en Ciénaga y otros lugares de la zona bananera debían levantarse "obeliscos conmemorativos de esa nefanda hecatombe". El Tiempo (Bogotá) 1 de diciembre de 1939: 10. Se desconoce si, en efecto, el monumento y los obeliscos fueron instalados.

42. Existen varias versiones sobre el origen del monumento. Una, ya mencionada, indica que este respondió a una iniciativa del MOIR que comprometió el esfuerzo de múltiples organizaciones sindicales del país. Otra versión indica que el monumento lo donó Rodrigo Arenas Betancourt sin destacar el papel del MOIR en la idea original y en la campaña para su elaboración e instalación. A esas dos versiones se debe agregar un ingrediente adicional: se afirma que el destino original del monumento era la conmemoración del aniversario de la revolución haitiana, "pero la estatua nunca salió hacia este país del Caribe y en la coyuntura de los cincuenta años de la masacre el artista la donó a Ciénaga”. Olmo Uscátegui Ramírez, “Banana Republic of Ciénaga. Ochenta años sin olvido de la United Fruit Company y la huelga y masacre de 1928" (Tesis de pregrado en Antropología, Pontificia Universidad Javeriana, 2012) 22-23. La versión sobre el destino original del monumento, afirma Uscátegui Ramírez, circuló en Ciénaga en el acto conmemorativo de 2008, con lo que se recreó una polémica presente desde hace tiempo entre la población acerca de la verdadera representatividad del monumento. Para una descripción sobre el origen del monumento (en donde se destaca el papel del MOIR), véase Hernán Pérez Zapata, ed., 80 años de la lucha y masacre en las bananeras (Ciénaga: Alcaldía Municipal de Ciénaga, 2008). 
país se realizaron concentraciones para evocar la fecha infeliz, como ocurrió en la plaza de toros de Bogotá. ${ }^{43}$ No obstante, el acto central de la conmemoración fue el que se realizó en la plaza central de Ciénaga el 6 de diciembre, al que asistieron, según informó Tribuna Roja, cerca de quince mil personas entre lugareños, activistas sindicales y militantes regionales y nacionales de todas las organizaciones de izquierda. ${ }^{44}$ En el evento intervinieron varios oradores, entre ellos, Jaime Piedrahita Cardona, candidato presidencial por el Frente por la Unidad del Pueblo, y Abel Rodríguez, militante del MOIR, quien expresó:

Medio siglo después de la heroica batalla, la lucha contra el imperialismo continúa. Devorada entre sus fauces desaparecía la soberanía del país al clarear la presente era de la humanidad, y hoy, al trasegar el último tercio de la centuria, sus garras siguen clavadas, más profundamente que antes, en el suelo colombiano. Resultado previsible de tan abominable situación es la gran crisis que estremece al viejo orden y cuyos síntomas han aflorado ya con pavor para los de arriba y esperanza para los de abajo. El gobierno de Turbay Ayala, más arrodillado ante sus amos yanquis y más represivo y corrupto que aquel que ordenó la masacre de las bananeras, expresa concretamente este descompuesto estado de cosas. ${ }^{45}$

De la intervención del dirigente sindical se resalta el interés de aprovechar la conmemoración para denunciar al gobierno de Julio César Turbay Ayala (1978) y el Estatuto de Seguridad, bajo el cual se ejecutaron numerosos allanamientos y encarcelamientos a dirigentes sociales en el país. Esa línea de interpretación era compartida por todas las organizaciones de izquierda (partidos, centrales obreras, defensores de derechos humanos, etc.). Por ejemplo, el PST consideraba que la jornada conmemorativa de la masacre era la "mejor oportunidad" para exigir al gobierno el levantamiento del estado de sitio, la derogación del Estatuto de Seguridad, la conclusión de los consejos verbales de guerra y la publicación de la lista de los detenidos. ${ }^{46}$

\subsection{Memorias en papel}

La coyuntura conmemorativa de 1978 sirvió para estimular la publicación de investigaciones sobre el acontecimiento de $1928 .{ }^{47} \mathrm{Al}$ respecto, aparecieron varios

43. "Aniversario de las bananeras", El Tiempo (Bogotá) 6 de diciembre de 1978: 9.

44. En la tarima que presidió el acto central en la plaza de Ciénaga, anota el periódico citado, ocuparon lugar "seis ancianos protagonistas de la batalla del 28 [...] Rafael Caraballo, Isaac Villamil Lara, Eligio Valiente, Álvaro Girón, Pedro Reales Campo y Guillermo Hernández”. "Cincuentenario de las bananeras: revolucionaria conmemoración en Ciénaga”, Tribuna Roja (Bogotá) febrero-marzo de 1979: 17.

45. "Cincuentenario de las bananeras" 17.

46. El Socialista (Bogotá) 31 de octubre de 1978: 5.

47. Antes de 1978 se publicaron algunos trabajos en que se referencia la masacre de las bananeras, como el ya citado de Torres Giraldo. En 1974 fue editado por el Centro de Estudios Sociales, 
trabajos de corte académico, pero con criterios interpretativos afines a la izquierda. Tres textos fueron elaborados en el marco conmemorativo de 1978, pese a que de los tres solo uno apareció ese año (los otros dos, tiempo después). El primero, Bananeras 1928-1978, fue elaborado por una comisión del Centro de Investigaciones Sociales (CEIS), integrada por Nicolás Buenaventura, Julio Silva Colmenares, Carlos Arango, Gilberto Morales y Francisco Sandoval, bajo la coordinación de Álvaro Delgado. ${ }^{48}$ Vinculados o cercanos al Partido Comunista y sin ser historiadores profesionales, pero con una trayectoria en el campo de la investigación sobre las luchas obreras en el país, los autores se propusieron elaborar una interpretación de la huelga bananera de 1928 en tres capítulos, que complementaron con un apartado final en el que se recogían documentos y testimonios vinculados al acontecimiento. En 1980 se publicó el libro Bananeras, testimonio vivo de una epopeya, de Gabriel Fonnegra, militante del MOIR, en el que abordó aspectos relacionados con la historia de la UFCO y su poder en la región bananera, así como el origen de la huelga y la masacre de los trabajadores en diciembre de $1928 .{ }^{49}$

En 1981 apareció Sobrevivientes de las bananeras, de Carlos Arango, periodista vinculado al Partido Comunista, en el que se recogieron testimonios de personas que participaron en la huelga de 1928. La particularidad de la investigación, que comenzó a ser elaborada probablemente antes de 1979, radica precisamente en la inclusión de las voces de testigos presenciales tanto de la huelga como de la masacre. ${ }^{50}$

Desde una perspectiva general, estas investigaciones, elaboradas por miembros de agrupaciones de izquierda (excepto la de White), cumplieron funciones diversas: sirvieron para que los militantes acudieran al hecho histórico a través de una interpretación "oficial" del mismo; nutrieron la memoria social del acontecimiento, al posibilitar, por ejemplo, que la masacre de las bananeras circulara entre diversos sectores sociales (sindicales, estudiantiles, intelectuales); enriquecieron los universos conmemorativos, $y$, finalmente, fueron una respuesta a los silencios oficiales, incluido el del campo académico, frente al suceso trágico. Como no había ocurrido antes, estas publicaciones no solo "recuperaron" el acontecimiento, sino que, tal vez sin proponérselo, ampliaron la bibliografia sobre el mismo, acudiendo, en algunos casos, al uso de metodologías diversas como la oralidad y la búsqueda de documentos primarios.

La lucha obrera ante la legislación laboral (Bogotá: Fundación Editorial Muisca, 1974), en el cual se dedica un apartado a la historia de la huelga bananera de 1928.

48. Confederación Sindical de Trabajadores de Colombia, Bananeras 1928-1978 (Bogotá: Ediciones Alcaraván, 1978).

49. Gabriel Fonnegra, Bananeras, testimonio vivo de una epopeya (Bogotá:Tercer Mundo, 1980). Apartes de la investigación de Fonnegra fueron publicados en la revista Teorema:Arte y Cultura en 1978.

50. Carlos Arango Z., Sobrevivientes de las Bananeras (Bogotá: Editorial Colombia Nueva, 1981). Antes de editarse como libro la investigación de Carlos Arango obtuvo el Premio Nacional de Periodismo Simón Bolívar en 1979. 


\section{2008: ¿Tienes la memoria chiquita?}

En 2008 se conmemoraron los ochenta años de la masacre de las bananeras. Las circunstancias políticas y sociales del país convirtieron el hecho en una ocasión especial, como había ocurrido en otras oportunidades. La fecha trágica se inscribió en la segunda presidencia de Álvaro UribeVélez, mandatario resistido por distintos sectores sociales y políticos y quien es acusado de tener vínculos con grupos paramilitares responsables del exterminio de dirigentes de izquierda. Para ese momento, ya era de conocimiento público la relación entre políticos regionales, multinacionales y grupos paramilitares, a raíz de las investigaciones judiciales (conocidas con el nombre de parapolítica) y académicas (como las de la Fundación Arco Iris), y de las confesiones de miembros de aquellos grupos. En especial, era ampliamente conocido el apoyo económico que dio la multinacional bananera Chiquita Brands (derivada de la antigua UFCO) a los paramilitares en Urabá, hecho sobre el que volveremos más adelante.

En los actos conmemorativos de 2008 participaron diversas organizaciones sociales locales ${ }^{51}$ y nacionales (defensoras de derechos humanos, medios de comunicación alternativa, organizaciones juveniles), así como agrupaciones de izquierda (Polo Democrático Alternativo) y de otras tendencias políticas reunidas en la Gran Coalición Democrática (de la que hacían parte sectores del Partido Liberal). Especial papel tuvo en la campaña conmemorativa la agrupación Hijos e Hijas por la Memoria y contra la Impunidad.

Los eventos en Ciénaga se iniciaron el 1 de diciembre y contemplaron múltiples actividades, entre las que sobresalieron actos religiosos, conferencias, foros, lanzamiento de libros, presentaciones musicales, veladas y exposiciones pictóricas y fílmicas. Los actos concluyeron con una movilización el 6 de diciembre a la que asistieron personas de distintos lugares del país y periodistas de informativos como Noticias Uno, Telesur y Contravía, entre otros. Un hecho local sobresaliente fue la vinculación de diferentes sectores y pobladores de Ciénaga, poseedores de lecturas diversas e incluso distintas sobre el impacto de la masacre, lo que garantizó una amplia representación de las interpretaciones en torno al hecho conmemorado.

Como había ocurrido en oportunidades anteriores, el interés por articular pasado y presente se hizo manifiesto en los actos de 2008. De hecho, los partidos y organizaciones de izquierda que hacían oposición al gobierno de Álvaro Uribe Vélez dotaron a la conmemoración de un alto sentido político. Por ejemplo, articularon la conmemoración de la masacre de las bananeras con el caso de la Chiquita Brands, multinacional que apoyó a grupos armados de derecha y que convirtió en objetivo militar al movimiento sindical y campesino del Urabá. Esa

51. La investigación de Olmo Uscátegui Ramírez describe e interpreta el papel que desempeñaron diversos sectores de Ciénaga (intelectuales, funcionarios públicos de la alcaldía, etc.) en los actos conmemorativos de 2008; indica, entre otras cosas, que estos no estuvieron sujetos a las agendas y actores externos. El dato es relevante porque da cuenta del peso identitario que existe en torno al hecho histórico en la localidad. 
idea conectora se plasmó en uno de los lemas oficiales que se adoptaron para la conmemoración de 2008: “¿Tienes la memoria chiquita?” De tal modo, se buscó establecer una relación de continuidad entre la masacre de 1928 y la responsabilidad de la UFCO, con los crímenes de sindicalistas y trabajadores financiados por la Chiquita Brands en los años 1990. Si en el pasado fue la UFCO promotora de muertes de trabajadores en Colombia, en tiempos recientes ese papel lo adoptó la empresa Chiquita Brands, que contaba con la complacencia y apoyo de las élites regionales y las fuerzas armadas. En una convocatoria que circuló por las redes se establecía esa idea de continuidad en los siguientes términos:

En la semana del 1 al 6 de diciembre se realizará en Ciénaga Magdalena una gran movilización nacional e internacional conmemorativa de los 80 años de la huelga y de rechazo a la masacre en las bananeras perpetrada por el Gobierno Colombiano en defensa de los intereses de la multinacional United Fruit Company, (hoy Chiquita Brands Continental Co.) y en condena a las políticas del Gobierno de Álvaro Uribe Vélez contra los derechos laborales y la vida de los trabajadores y el pueblo Colombiano y en contra de la insistencia de su Gobierno en la aprobación del TLC impuesto por E.U. en beneficio de sus multinacionales saqueadoras de la riqueza, producción y trabajo nacionales. ${ }^{52}$

El interés de conectar las dos coyunturas (1928 y 2008) condujo a que los promotores de los actos conmemorativos formularan comparaciones entre los protagonistas de uno y otro momento:

\footnotetext{
Mucho se ha escrito acerca de la Masacre de las Bananeras, la realidad de los hechos ha dejado sólo una enseñanza, la naturaleza criminal del imperialismo [...] Rememorar este hecho luctuoso, en la historia de Colombia, en donde las armas de Oficiales masacraron a los obreros nacionales, en defensa de los intereses de una compañía extranjera, la United Fruit Company hace 80 años, a manos del General Cortés Vargas en obedecimiento a órdenes de los norteamericanos, debe pasar por la recordación de las masacres llevadas a cabo en la Zona Bananera del Urabá por el general Rito Alejo del Río, en connivencia con las hordas paramilitares, fomentadas por el entonces Gobernador de Antioquia Álvaro Uribe Vélez..$^{53}$
}

\subsection{De nuevo la memoria impresa}

El marco conmemorativo de los 80 años de la masacre de las bananeras estimuló la aparición de nuevas publicaciones sobre el acontecimiento. Sin embargo, estas no tuvieron el marcado carácter militante que distinguió a aquellas que circularon en torno a los actos de $1978 .{ }^{54}$ La principal publicación fue Bananeras. Huelga y

52. https://www.skyscrapercity.com/showthread.php?t=760570\&page=3 (19/10/2017).

53. Declaración del Comité de Base Alfredo Correa D’Andreis, reproducida en Uscátegui 34.

54. Entre las dos fechas (1978 y 2008) aparecieron pocas publicaciones sobre la masacre. En 1999 


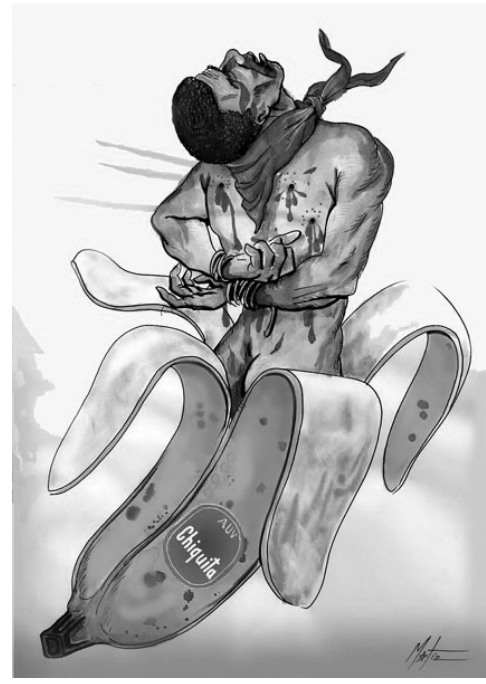

Fuente: Archivo del autor.

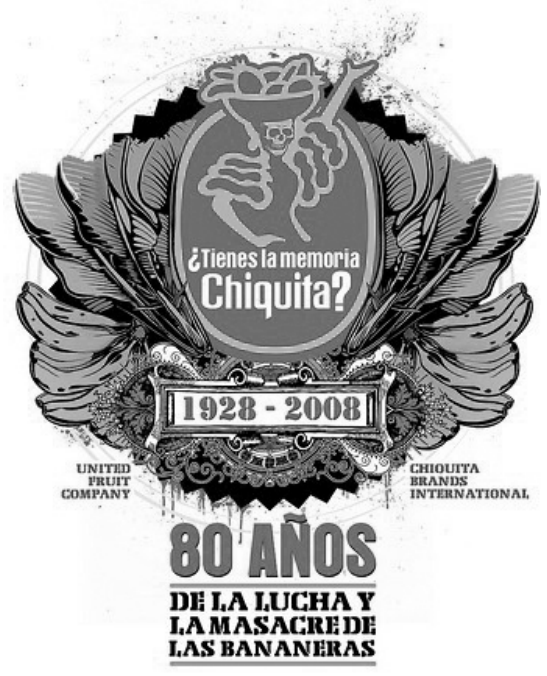

Fuente: Archivo del autor.

masacre 80 años, que se derivó de un evento realizado en la Universidad Nacional en Bogotá en el que participaron académicos con amplia trayectoria investigativa en la historia social junto a noveles historiadores. En el libro se reunieron análisis que trataron aspectos relacionados con la huelga bananera y con los hechos del 6 de diciembre de 1928, pero, además, sobre aspectos poco explorados como el acaparamiento de la tierra y la apropiación del agua que hizo la UFCO en la zona, y su incidencia en el ambiente de inconformidad previo a la huelga, el papel de la Iglesia católica frente al conflicto laboral, las primeras representaciones que se hicieron de la masacre y su presencia en la literatura nacional, entre otros. Por la diversidad de perspectivas contempladas, y pese al carácter preliminar de algunos de los textos que la componen, la obra marcó un quiebre respecto de las producciones publicadas anteriormente al abrir nuevas posibilidades para continuar explorando un tema que, a esas alturas, parecía ya agotado.

En la costa norte también se publicaron algunas investigaciones sobre la masacre, lo cual es un indicador de la persistencia del hecho histórico en los ambientes académicos e intelectuales de la región..$^{55}$ En particular, esas publicaciones testimonian la presencia de un grupo de intelectuales cienagueros y del departamento del Magdalena que ha promovido lecturas no siempre coincidentes sobre la dimensión

fue publicado un capítulo dedicado a la persistencia de la memoria de la huelga bananera en el libro de Carlos Rodolfo Ortega Montero, La lírica política en la historia de Colombia (Bogotá: Imprenta Nacional de Colombia, 1999).

55. Por ejemplo, Carlos Payares González, ed., Memoria de una epopeya: 80 años de la huelga y masacre de las bananeras (Ciénaga: Alcaldía Municipal de Ciénaga, 2008), y la obra colectiva 80 años de la lucha y la masacre en las bananeras, ya referenciada. 
Figura 5. Afiche del simposio "Bananeras. Huelga y masacre. 80 años"

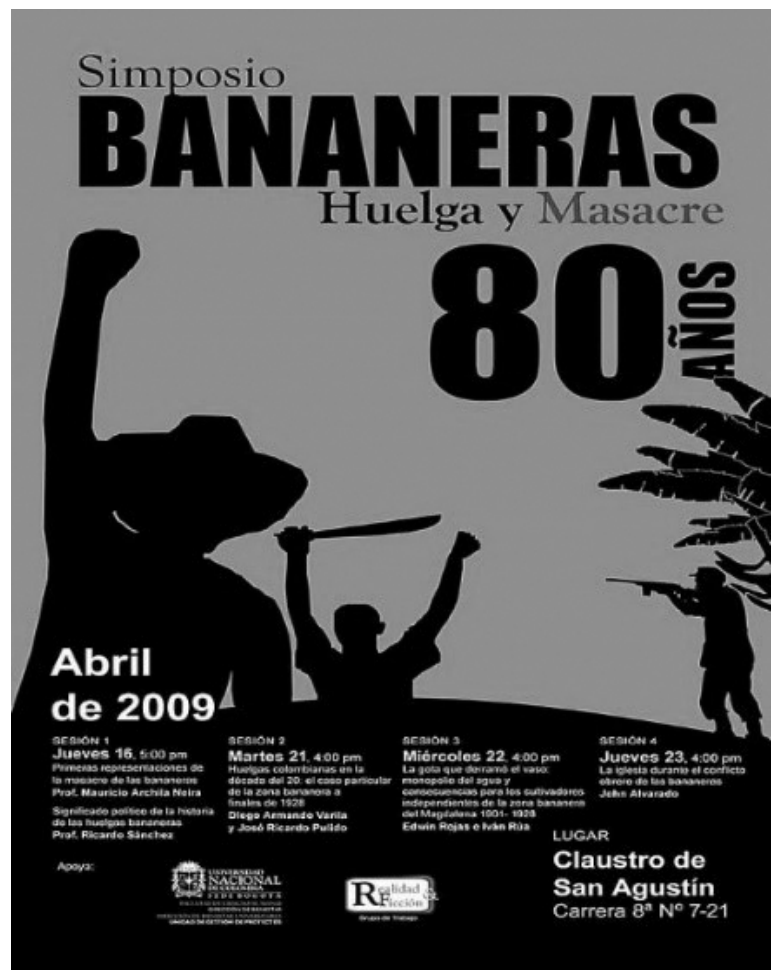

Fuente: Archivo del autor.

y significado de la masacre de 1928. No obstante, y así lo señala Olmos Uscátegui, su presencia ha sido fundamental para el caso de Ciénaga, en cuanto que son "las personas que han construido el conocimiento histórico en el municipio". ${ }^{56}$

Dos años después de la fecha conmemorativa se publicó en español una investigación de Peter Chapman sobre la historia de la UFCO y las arbitrariedades que la acompañaron, ${ }^{57}$ con lo cual se mostraba que el tema bananero - así no se abordase allí la masacre de 1928 como acontecimiento- continuaba despertando el interés académico. Aunque la publicación fue posterior a los eventos conmemorativos de 2008 (apareció originalmente en inglés en 2007), tenía en común con aquellos establecer la conexión entre la UFCO y la Chiquita Brands, y la relación de esta última con los grupos paramilitares. Un relato que, como vimos, nutrió el imaginario de las organizaciones políticas y sociales que promovieron los actos conmemorativos de 2008 .

56. Olmo Uscátegui interpreta el significado de lo que él denomina "campo académico, artístico y sindical dedicado a investigar el pasado del municipio", mediante discursos diversos sobre la masacre y el significado de la UFCO. Uscátegui 22 y 61.

57. Peter Chapman, Bananas: de cómo la United Fruit Company moldeó el mundo (Bogotá:Taurus, 2010). 
Figura 6. Mural conmemorativo de los 80 años de la masacre de las bananeras, sur de Bogotá

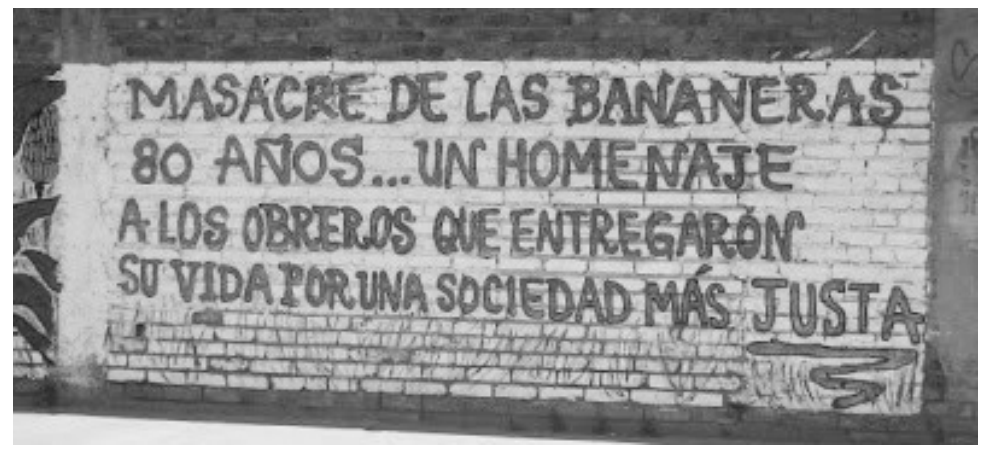

Foto: Fotografia del autor, 2008.

\section{Conclusión}

La evocación de la masacre de las bananeras entre 1929 y 2008 puso en evidencia hechos de interés para reflexionar acerca de la forma como los grupos sociales recuerdan el pasado y las consecuencias que se derivan de esa práctica. En el artículo se indagó por el sentido que otorgaron ciertos sectores sociales al hecho histórico y la forma como este fue reinterpretado y representado. Como se mostró, fueron sectores de la clase trabajadora, junto a intelectuales de izquierda y estudiantes, quienes más se comprometieron con la conmemoración de la masacre al concebirla como un "deber de memoria" que estaba articulado a un "deber de justicia".

Que hayan sido especialmente sectores laborales los más interesados en recordar la fecha se explica por un sentimiento de solidaridad de clase con los que fueron asesinados. Aquí opera un comportamiento que referenció Paul Ricoeur: "Debemos a los que nos precedieron una parte de lo que somos. El deber de memoria no se limita a guardar la huella material, escrituraria u otra, de los hechos pasados, sino que se cultiva el sentimiento de estar obligados respecto a estos otros de los que afirmaremos más tarde que ya no están pero que estuvieron".$^{58}$ Esa solidaridad fortaleció la idea de un deber ético de memoria, el cual logró extenderse a otros sectores sociales que dieron fortaleza a los actos conmemorativos.

Las conmemoraciones de 1978 y de 2008 mostraron la vitalidad de la memoria en torno a la masacre de las bananeras en los movimientos de izquierda del país. Esa vitalidad estuvo conectada, sin duda, a las coyunturas políticas en las que se enmarcaron los actos de recordar. En los tres momentos que se estudiaron, la memoria de la masacre fue convertida en un recurso para dinamizar las confrontaciones políticas: en 1929 sirvió para deteriorar la imagen del gobierno conservador de Miguel Abadía Méndez; en 1978 para denunciar al gobierno de Julio César Turbay 
Ayala y el Estatuto de Seguridad; finalmente, en 2008 para confrontar al gobierno de Álvaro Uribe Vélez y políticas de su administración, como la Seguridad Democrática y la firma de los Tratados de Libre Comercio.

Lo anterior estuvo acompañado de una resemantización del pasado, es decir, de una reinterpretación del acontecimiento histórico de 1928, determinado por las singularidades del presente en que estaban inmersos los actores conmemorativos. Esa resemantización tuvo el poder de guardar la "apariencia de continuidad" del acontecimiento (masacre de las bananeras) en los momentos posteriores. Que así haya ocurrido abre un interrogante formulado por José Colmeiro, que debería ser explorado con detenimiento: ¿hasta qué punto un acontecimiento ha sido constituido como tal por los efectos de la memoria? ${ }^{59}$

Por último, se pudo constatar que en el ejercicio de recordar la masacre de las bananeras se fortalecieron identidades políticas de quienes participaron en las prácticas conmemorativas. Por ejemplo, los trabajadores reforzaron sus concepciones en torno al papel del Estado y las élites dominantes (vistas en conjunto como "asesinas", "represoras", etc.) y fortalecieron sentimientos como el anticapitalismo y antimperialismo (de vieja data en el país), que se tradujeron en posturas de rechazo a políticas como los TLC y la presencia de multinacionales en el territorio colombiano. En sectores sociales ligados a la defensa de los derechos humanos la conmemoración de la masacre permitió alimentar narrativas sobre el papel del Estado en la persecución y desaparición de activistas y reivindicar la necesidad de políticas a favor de la defensa de la memoria colectiva.

\section{Fuentes}

\section{Periódicos y revistas}

Alternativa (Bogotá) 1978.

El Socialista (Bogotá) 1978.

El Tiempo (Bogotá) 1929, 1978.

La Prensa (Barranquilla) 1929.

Tribuna Roja (Bogotá) 1979.

Universidad (Bogotá) 1929.

\section{Bibliografía}

Arango Z., Carlos. Forjadores de la revolución colombiana. Bogotá: Editorial Colombia Nueva, 1983. Sobrevivientes de las bananeras. Bogotá: Editorial Colombia Nueva, 1981.

59. José F. Colmeiro, Memoria histórica e identidad cultural. De la posguerra a la postmodernidad (Barcelona:Anthropos, 2005) 46. 
Archila Neira, Mauricio y Leidy Torres Cendales. Eds. Bananeras. Huelga y masacre. 80 años. Bogotá: Universidad Nacional de Colombia, 2009.

Archila Neira, Mauricio. "Primeras representaciones de la masacre de las bananeras". Bananeras. Huelga y masacre. 80 años. Eds. Mauricio Archila Neira y Leidy Torres Cendales. Bogotá: Universidad Nacional de Colombia, 2009.

Braun, Herbert. Mataron a Gaitán. Vida pública y violencia urbana en Colombia. Bogotá: Universidad Nacional de Colombia, 1987.

Castrillón, Alberto. 120 días bajo el terror militar o la huelga de las bananeras. Bogotá: Revista Universidad, 1929.

Centro de Estudios Sociales. La lucha obrera ante la legislación laboral. Bogotá: Fundación Editorial Muisca, 1974.

Colmeiro, José F. Memoria histórica e identidad cultural. De la posguerra a la postmodernidad. Barcelona: Anthropos, 2005.

Colmenares, German. Ricardo Rendón: una fuente para la historia de la opinión pública. Bogotá: Tercer Mundo / Universidad del Valle / Banco de la República, 1998.

Confederación Sindical de Trabajadores de Colombia. Bananeras 1928-1978. Bogotá: Editorial Alcaraván, 1978.

Cordell Robinson, Joy. El movimiento gaitanista en Colombia (1930-1948). Bogotá: Tercer Mundo, 1976.

Chapman, Peter. Bananas: de cómo la United Fruit Company moldeó el mundo. Bogotá: Taurus, 2010.

Fonnegra, Gabriel. Bananeras, testimonio vivo de una epopeya. Bogotá:Tercer Mundo, 1980.

Gaitán, Jorge Eliécer. El debate sobre las bananeras. Cuatro de días de verdad contra 40 años de silencio. Bogotá: Centro Cultural Jorge Eliécer Gaitán, 1988.

- Lágrimas y sangre, o, las matanzas en las bananeras: compilación de los debates en el congreso alrededor de los procesos militares. Cali: Ediciones de la Tipografia Gutenberg, 1929.

García Márquez, Gabriel. Cien años de soledad. Buenos Aires: Editorial Suramericana, 1967.

Green, William John. Gaitanismo, liberalismo de izquierda y movilización popular. Medellín: Fondo Editorial Universidad EAFIT / Banco de la República, 2013.

Halbwachs, Maurice. Los marcos sociales de la memoria. Barcelona: Anthropos, 2004. Low Padilla, Carlos Alfonso. “Conflictos agrarios en la zona bananera: 1910-1947”. Tesis de grado en Sociología, Universidad Nacional de Colombia, 1972. Medina, Medófilo. Historia del Partido Comunista Colombiano. Bogotá: Centro de Estudios e Investigaciones Sociales, 1980.

. La protesta urbana en Colombia en el siglo XX. Bogotá: Ediciones Aurora, 1984.

Mejía, Juan Diego. Soñamos que vendrían por el mar. Bogotá: Alfaguara, 2016.

Meschkat, Klaus y María Rojas. Comps. Liquidando el pasado. La izquierda colombiana en los archivos de la Unión Soviética. Bogotá:Taurus / Fescol, 2009. 
Michonneau, Stéphane. "La memoria, ¿objeto de historia?”. Identidades y memoria imaginada. Eds. Justo Beramendi y María Jesús Baz.Valencia: Universitat de Valencia, 2008.

Ortega Montero, Carlos Rodolfo. La lírica política en la historia de Colombia. Bogotá: Imprenta Nacional de Colombia, 1999.

Osorio Lizarazo, José Antonio. Gaitán, vida, muerte y permanente presencia. Bogotá: Carlos Valencia Editores, 1979.

Parra Salazar, Mayra Natalia. ;A teatro camaradas! Dramaturgia militante y política de masas en Colombia (1965-1975). Medellín: Fondo Editorial FCSH, 2015.

Payares González, Carlos. Ed. Memoria de una epopeya: 80 años de la huelga y masacre de las bananeras del Magdalena. Ciénaga:Alcaldía Municipal de Ciénaga, 2008.

Pérez Zapata, Hernán. Ed. 80 años de la lucha y masacre en las bananeras. Ciénaga: Alcaldía de Ciénaga, 2008.

Pernett, Nicolás. "La masacre de las bananeras en la literatura colombiana". Bananeras. Huelga y masacre. 80 años. Eds. Mauricio Archila Neira y Leidy Torres Cendales. Bogotá: Universidad Nacional de Colombia, 2009.

Perry, Santiago. Comp. Escritos políticos. Bogotá: El Áncora Editores, 1985.

Ricoeur, Paul. La memoria, la historia, el olvido. Buenos Aires: Fondo de Cultura Económica, 2008.

Tirado Mejía,Álvaro. Los años sesenta. Una revolución en la cultura. Bogotá: Debate, 2014. Torres Giraldo, Ignacio. Los inconformes. Historia de la rebeldía de masas en Colombia. Tomo 4. Bogotá: Editorial Latina, 1978.

Traverso, Enzo. El pasado, instrucciones de uso. Historia, memoria, política. Barcelona: Marcial Pons, 2007.

Uscátegui Ramírez, Olmo. "Banana Republic of Ciénaga. Ochenta años sin olvido de la United Fruit Company y la huelga y masacre de 1928”. Tesis de pregrado en Antropología, Pontificia Universidad Javeriana, 2012.

Vega Cantor, Renán. Gente muy rebelde. Tomo 3. Bogotá: Pensamiento Crítico, 2002. White, Judith. Historia de una ignominia: la United Fruit Co. en Colombia. Bogotá: Editorial Presencia, 1978. 